\title{
Especialização produtiva: potenciais e desafios para 0 estado do Rio de Janeiro
}

\author{
Lia Hasenclever ${ }^{1}$ \\ Henrique Cavalieri ${ }^{2}$ \\ Ricardo Torres $^{3}$ \\ Heitor Mendes ${ }^{4}$
}

\begin{abstract}
Sumário
0 estado do Rio de Janeiro (ERJ) especializou-se na produção de bens intermediários, com ênfase na indústria de extração e refino de petróleo. 0 objetivo do artigo é analisar as especificidades das mudanças estruturais ocorridas e discutir a capacidade de o ERJ sustentar o desenvolvimento futuro. A especialização excessiva pode truncar os efeitos de encadeamento da indústria, mas a acumulação de capacitacões sociais e tecnológicas na exploração do petróleo pode abrir caminho para o desenvolvimento de outras indústrias e o investimento em bens coletivos e infraestrutura que propiciem a diversificação industrial e o bem estar da populacão. A experiência histórica e a análise das políticas atuais deixam claro que, sem o direcionamento das políticas públicas e privadas, o desenvolvimento futuro do ERJ estará fadado a um padrão de desenvolvimento com baixo crescimento da demanda agregada e mudança estrutural limitada a enclaves, ainda que o crescimento de produtividade seja alto em algumas atividades.
\end{abstract}

Palavras-chave: mudança estrutural, especialização, recursos naturais, políticas públicas; desenvolvimento sustentável.

\begin{abstract}
The state of Rio de Janeiro (SRJ) has specialized in the production of intermediate goods, with an emphasis on the extraction and refining of petroleum. The aim of this paper is to analyze the specificities of structural changes and discuss the ability of the SRJ sustain future development. The excessive specialization can truncate the linkage effects of industry, but the accumulation of social and technological capabilities in oil exploration could pave the way for the development of other industries and investment in collective goods and infrastructure that facilitate the industrial diversification and welfare of the population. The historical experience and the analysis of current policies make it clear that without the targeting of public and private policies, future development of the SRJ will be bound to a pattern of development with low aggregate demand growth and structural change limited to enclaves, although the productivity growth is high in some activities.
\end{abstract}

Keywords: structural change, specialization, natural resources, public policy, sustainable development.

\section{Introdução}

O Brasil, assim como vários outros países emergentes, tem se beneficiado do aumento da demanda e dos preços internacionais de commodities agrícolas e minerais. $\mathrm{O}$ estado do Rio de Janeiro (ERJ), em particular, é o estado onde as mudanças estruturais são mais intensas em direção à especialização produtiva em bens intermediários, com ênfase na indústria extrativa a partir da descoberta de jazidas de petróleo e gás natural na Bacia de Campos. Essa especialização produtiva, como aponta a literatura, pode ser problemática para o desenvolvimento industrial de longo prazo devido a sua incapacidade de irradiar o

\footnotetext{
1 Professora Colaboradora, Instituto de Economia, Universidade Federal do Rio de Janeiro, e Universidade Cândido Mendes, lia@ie.ufrj.br.

2 Aluno de doutorado, Programa de Pós-graduação em Economia, Universidade Federal do Rio de Janeiro, henrique.cavalieri@ gmail.com.

3 Aluno de doutorado, Programa de Pós-graduação em Economia, Universidade Federal do Rio de Janeiro, rcd.torres@gmail.com.

4 Aluno de doutorado, Programa de Pós-graduação em Políticas Públicas, Estratégias e Desenvolvimento, Universidade Federal do Rio de Janeiro, heitor.mendes@pped.ie.ufrj.br.
} 
desenvolvimento, ampliando seus efeitos para outras indústrias locais, a sua caraterística de indústria internacionalizada e ao fato dela estar sujeita à enorme volatilidade dos preços internacionais das commodities.

Todavia, esta mesma literatura sobre o tema chama atenção para dizer que esta não é uma situação inexorável e se estas economias conseguirem diversificar suas atividades, ampliar o uso de insumos de conteúdo local e ampliar suas capacidades na oferta de bens coletivos e infraestrutura elas poderão afastar-se da "maldição" dos recursos naturais ou da "doença holandesa".

A literatura já apresentou diversas discussões e evidências de que a diversificação das atividades industriais é intrínseca ao conceito de desenvolvimento econômico em si, tomado como um processo relacionado à ampliação do emprego e da capacidade produtiva, com contínua elevação da produtividade e mudança estrutural com viés para os setores intensivos em capital e tecnologia. Entretanto, nem sempre este processo é automático, principalmente quando o desenvolvimento apresenta uma especialização baseada na descoberta de recursos naturais (Evans, 2010). Há que se impulsionar a diversificação através de políticas de conteúdo local. Além disso, é necessária que ocorra, em simultâneo, uma ampliação das capacidades produtivas das empresas e bens públicos coletivos que permitam o engajamento do tecido industrial local e a sustentação da demanda. Enfim, para o gerenciamento adequado deste tipo de desenvolvimento é inevitável participação ativa do Estado, não a expensas do mercado, mas em simultâneo com este.

Como indica o documento da Comissão Econômica para a América Latina e o Caribe (CEPAL, 2012), pode haver de fato diferentes padrões de crescimento associados ao tipo ou intensidade de mudança estrutural em curso em uma determinada economia. Alguns padrões de crescimento são mais dinâmicos do que outros, sendo que a combinação de uma estrutura de oferta inovadora (eficiência schumpeteriana) e uma demanda pujante (eficiência keynesiana) permitiria o melhor desempenho da economia. A avaliação de uma mudança estrutural deve estar assentada, de um lado, na caracterização dos níveis de produtividade obtidos pelo país, e, de outro, na evolução da demanda agregada e do emprego da economia.

Assim, um processo de expansão "virtuoso" indica uma mudança estrutural forte, em que produtividade e emprego crescem simultaneamente, combinando elevado crescimento da demanda agregada e maior participação de setores mais produtivos. Essa mudança proporciona o surgimento de novas atividades com maior produtividade e que absorvem empregos mais bem remunerados, reduzindo as desigualdades de renda internas ao país, bem como a brecha externa de produtividade em relação aos demais países. Tais atividades estão geralmente associadas a segmentos industriais e de serviços intensivos em conhecimento. No caso de uma mudança estrutural nula, a economia fica presa em um "círculo vicioso", no qual baixo crescimento da demanda agregada e estagnação da produtividade se retroalimentam. Os casos intermediários são os de mudança estrutural limitada a enclaves, que caracteriza um padrão de crescimento do tipo "ajuste defensivo", pois combina baixos patamares de demanda agregada com a modernização e expansão da produtividade de apenas algumas atividades, e, por fim, mudança estrutural débil, em que, apesar de haver a expansão da demanda agregada (muitas vezes externa), há uma estagnação da produtividade, indicando um padrão de crescimento do tipo "absorção de emprego" (CEPAL, 2012).

Para os países da América Latina e África (CEPAL, 2012; Evans, 2010), pode-se dizer que predomina em suas histórias recentes a interpolação de ciclos em que ora há crescimento da demanda agregada com aumento do emprego, ora expansão da produtividade em setores específicos, sendo que a manutenção simultânea e sustentável de criação de empregos e aumento da produtividade raramente se verifica nas regiões.

O objetivo do artigo é mostrar, frente à economia brasileira, quais são as especificidades das mudanças estruturais ocorridas na economia fluminense, os seus desafios e as políticas públicas voltadas para superar estes desafios e afastar a maldição dos recursos naturais. A pergunta que se quer responder é até que ponto uma economia baseada em especialização produtiva de exploração de recursos naturais, como é o caso da economia fluminense, é capaz de apresentar um desenvolvimento sustentável e dinâmico no longo prazo?

A metodologia utilizada foi uma revisão da literatura sobre o fenômeno da mudança estrutural baseada em recursos naturais, a análise de dados secundários econômicos e sociais sobre a economia do ERJ, relativos ao período 1996-2010, de documentos e de polí- 
ticas públicas voltadas para o estímulo ao encadeamento local da exploração do petróleo e gás (P\&G). $O$ foco da análise dirigiu-se para as dificuldades geradas pela especialização e pela programação das políticas públicas devido às características de uma indústria fortemente internacionalizada.

O artigo está estruturado em três seções, além da introdução e da conclusão. Na segunda seção apresentam-se os dados secundários econômicos e sociais com o objetivo de mostrar a mudança estrutural que resultou na especialização produtiva do ERJ em contraponto com a economia brasileira e discutem-se os seus desafios para o seu desenvolvimento. $\mathrm{Na}$ terceira seção, apresentam-se as principais características da indústria do P\&G e seus encadeamentos locais e internacionais. Na quarta seção - composta de duas subseções -, apresentam-se, inicialmente, as políticas voltadas para o aumento do conteúdo local e, a seguir, os indicadores de renda e emprego, saúde e educação e as dificuldades desta economia em alcançar um desenvolvimento virtuoso e transformador das condições socioeconômicas de sua indústria e população.

\section{Especialização industrial no Rio de Janeiro e seus desafios}

A análise da indústria fluminense e o contraponto com a indústria nacional são apresentados de acordo com as categorias de uso do Instituto Brasileiro de Geografia e Estatística (IBGE). As indústrias extrativas e de transformação $0^{5}$ foram agrupadas nas cinco categorias de uso do IBGE com base na tabela de correspondências da Comissão Nacional de Classificações. ${ }^{6}$

A Tabela 1 mostra a participação de cada categoria de uso no valor bruto da produção industrial (VBPI) para o Brasil e o ERJ em anos selecionados. Os pontos a destacar são os seguintes: em primeiro lugar, o setor de bens intermediários tem não só um peso maior na produção industrial do ERJ em comparação com o observado na indústria brasileira, mas também aumentou expressivamente sua participação recentemente: em 1996, essa indústria representava 55,4\% da produção industrial fluminense, atingindo 70,8\% em 2007. Boa parte desse crescimento deve-se ao aumento expressivo da produção nas indústrias de extração e refino de petróleo, classificadas aqui como indústrias de bens intermediários.

Tabela 1: Participação relativa (\%) das categorias de uso no VBPI: Brasil e ERJ (1996, 2003 e 2007)

\begin{tabular}{lrrrrrrr} 
Categoria de uso & $\mathbf{1 9 9 6}$ & & $\mathbf{2 0 0 3}$ & & $\mathbf{2 0 0 7}$ \\
& Brasil & ERJ & Brasil & ERJ & \multicolumn{1}{c}{ Brasil } & ERJ \\
Bens de capital & 9,8 & 7,0 & 11,4 & 10,3 & 12,9 & 10,8 \\
Bens de consumo duráveis & 11,8 & 2,3 & 8,2 & 2,1 & 9,0 & 3,5 \\
Bens de consumo não duráveis & 26,7 & 30,5 & 21,4 & 15,2 & 20,9 & 13,0 \\
Bens de consumo semiduráveis & 3,6 & 4,9 & 3,1 & 3,0 & 2,2 & 1,9 \\
Bens intermediários & 48,1 & 55,4 & 55,9 & 69,4 & 55,0 & 70,8
\end{tabular}

Fonte: Elaborado pelo Grupo de Economia da Inovação (IE/UFRJ) com base na Pesquisa Industrial Anual, IBGE (1996-2007)

Em segundo lugar, nota-se também o aumento da participação da indústria de bens de capital na economia fluminense, passando de $7 \%$ para quase $11 \%$. Apesar do crescimento dessa indústria, sua participação relativa é ainda inferior à observada na indústria brasileira. Por fim, verifica-se um pequeno aumento de participação dos bens de consumo duráveis no ERJ, que se deve principalmente à produção de veículos automotores iniciada em 1996 com a fábrica de caminhões da Volkswagen e posteriormente com a instalação de veículos de passeio da Peugeot-Citröen em 2001.

As elevadas e crescentes participações do segmento de bens intermediários na indústria

5 Desagregadas ao nível quatro de agregação da Classificação Nacional de Atividades Econômicas - CNAE.

60 período de análise vai de 1996 a 2007, baseada nos dados da Pesquisa Industrial Anual (PIA). Os dados mais recentes não foram incluídos por incompatibilidade na comparação entre as versões 1.0 e 2.0 da CNAE. 
do ERJ indicam um maior grau de especialização da estrutura produtiva fluminense em comparação com a nacional. Considerando-se a representatividade dos principais setores da indústria, constata-se que, em 1997, os quatro maiores setores industriais do ERJ ${ }^{7}$ respondiam por $57,9 \%$ do VBPI. Em 2007, esse número se elevou para $61,9 \%$. Em nível nacional, os quatro maiores setores industriais representavam 48,8\% do VBPI em 1997, mantendo-se praticamente constante em 2007 (48,7\%). Além disso, convém ressaltar que houve forte mudança estrutural na indústria fluminense, conforme demonstrado na Tabela 2. Em 1997, as duas maiores indústrias eram a fabricação de produtos químicos (18,5\% do VBPI) e de alimentos e bebidas $(16,3 \%)$. Em 2007, a extração de petróleo e a fabricação de coque, refino de petróleo e outros combustíveis encabeçavam a lista, totalizando 38,4\% do VBPI fluminense. A metalurgia básica se manteve como a terceira mais importante com pequena redução na participação relativa. A indústria de produtos químicos, apesar de ter reduzido seu peso relativo, ainda se mantém entre as quatro mais importantes do ERJ. Ressalta-se que as três maiores indústrias do ERJ são baseadas em recursos naturais e que as quatro indústrias podem ser classificadas como produtoras de bens intermediários, o que reforça a vocação fluminense na produção de commodities.

Tabela 2: Participação relativa (\%) dos quatro maiores setores no VBPI:ERJ (1997 e 2007)

\begin{tabular}{|c|c|c|c|}
\hline CNAE 1.0 & 1997 & CNAE 1.0 & 2007 \\
\hline 24 Fabricação de produtos químicos & 18,5 & 11 Extração de petróleo e serviços relacionados & 21,0 \\
\hline 15 Fabricação de produtos alimentícios e bebidas & 16,3 & $\begin{array}{l}23 \text { Fabricação de coque, refino de petróleo, elaboração de } \\
\text { combustiveis nucleares e produção de álcool }\end{array}$ & 17,4 \\
\hline 27 Metalurgia básica & 13,9 & 27 Metalurgia básica & 11,8 \\
\hline 22 Edição, impressão e reprodução de gravações & 9,1 & 24 Fabricação de produtos químicos & 11,7 \\
\hline Total & 57,8 & Total & 61,9 \\
\hline
\end{tabular}

Fonte: Elaborado pelo Grupo de Economia da Inovação (IE/UFRJ) com base na Pesquisa Industrial Anual, IBGE $(1997,2007)$

Outro destaque foi o forte crescimento da produtividade do trabalho na indústria de bens intermediários no ERJ, que em 1996 era de R 233 mil por pessoal ocupado, passando para R $\$ 425$ mil em 2007, conforme Tabela 3. Verifica-se um bom desempenho também na indústria de bens duráveis, cuja produtividade saltou de R\$ 78 mil, em 1996, para 218 mil, em 2007. A indústria de bens de capital, por sua vez, apesar da redução da produtividade entre 2003 e 2007, ainda manteve-se em um elevado patamar, R\$ 199 mil. Esses dados refletem o forte crescimento da indústria extrativa, refino de petróleo, metalurgia e siderurgia (bens intermediários), outros equipamentos de transporte, com especial participação da indústria naval (bens de capital) e fabricação e montagem de automóveis (bens de consumo duráveis).

Por outro lado, o ERJ experimentou uma redução da produção em vários setores industriais, entre os quais se destacam as indústrias de móveis, têxteis, vestuário, madeira, fumo, alimentos e bebidas (bens não duráveis e semiduráveis) e indústria química (especialmente produtos farmacêuticos).

A mudança estrutural da indústria no ERJ resultou em um desempenho econômico curioso. Analisando-se exclusivamente o crescimento do produto industrial, a economia fluminense cresceu a taxas superiores ao agregado nacional, graças ao forte crescimento das indústrias extrativas e das indústrias de transformação a elas associadas (exceto automóveis), conforme demonstrado no Gráfico 1. Entre 1995 e 2010, a produção industrial fluminense havia registrado um crescimento acumulado de $67 \%$, enquanto a indústria nacional cresceu apenas $47 \%$ no mesmo período. No entanto, quando analisado o comportamento do pib como um todo, o desempenho do ERJ foi aquém do observado em nível nacional, indicado também no Gráfico 1. Em 2010, o crescimento acumulado do PIB fluminense foi de $37 \%$ em relação a 1995, enquanto para o nível nacional o crescimento acumulado foi de $55 \%$. Isso demonstra que o forte desempenho das indústrias baseadas em recursos naturais no ERJ não foi acompanhado pelos outros setores de atividades, possivelmente por causa

7 Terceiro nível de agregação da CNAE grupos. 
de limitações nos efeitos de encadeamento a jusante e a montante na cadeia de valor e pela redução absoluta na produção de outras indústrias de transformação.

Tabela 3: Produtividade do trabalho na indústria por categoria de uso (VBPI/PO, R\$ 1.000): ERJ (1996, 2003 e 2007)

\begin{tabular}{lrrr} 
Categoria de uso & 1996 & $\mathbf{2 0 0 3}$ & $\mathbf{2 0 0 7}$ \\
Bens de capital & 138 & 211 & 199 \\
\hline Bens de consumo duráveis & 78 & 130 & 210 \\
\hline Bens de consumo não duráveis & 161 & 136 & 126 \\
Bens de consumo semiduráveis & 223 & 250 & 219 \\
Bens intermediários & 233 & 411 & 425 \\
Total & 189 & 280 & 286
\end{tabular}

Obs: Valores nominais foram atualizados pelo IPA-OG (FGV), preços constantes de 2009.

Fonte: Elaborado pelo Grupo de Economia da Inovação (IE/UFRJ) com base na Pesquisa Industrial Anual - IBGE (1996-2007)

Gráfico 1: Evolução do PIB e do índice do produto real da indústria (base 1995=100): Brasil e ERJ (1995-2010)

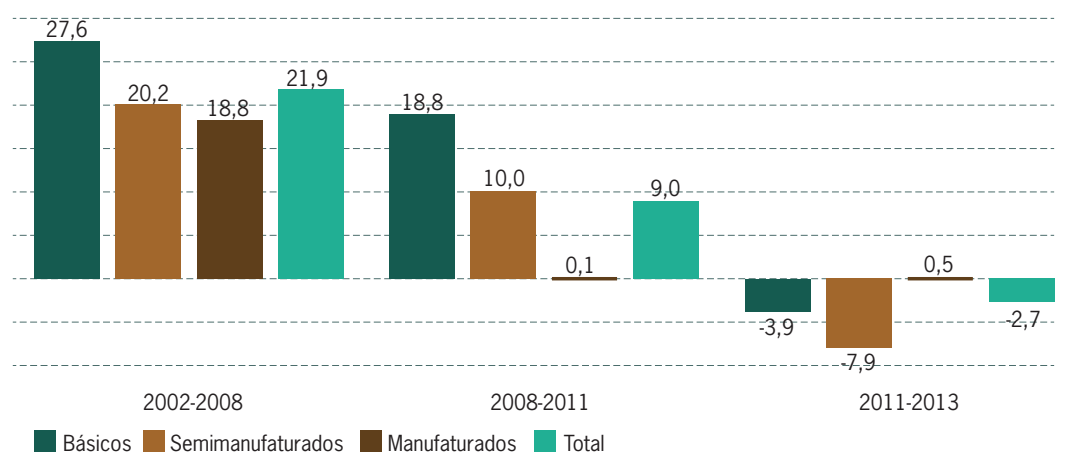

Fonte: Elaborado pelo Grupo de Economia da Inovação (IE/UFRJ) com base na retropolação das contas nacionais e regionais e na Pesquisa Industrial Mensal - Produção Física, IBGE (1995-2010)

Outra hipótese que poderia ser levantada é que não estaria havendo na economia fluminense um direcionamento, das políticas públicas e privadas, capaz de promover uma mudança estrutural virtuosa, onde os ganhos com a economia do petróleo estariam sendo canalizados para sustentar também um forte crescimento da demanda agregada, em conjunto com a mudança estrutural e os aumentos de produtividade.

Na literatura econômica, encontra-se uma série de explicações para o fracasso no desenvolvimento econômico de países ricos em recursos naturais. Apontam-se como principais "maldições" ou desvantagens de se possuir abundância em recursos naturais: o perigo da doença holandesa; rent seeking e baixo capital social; baixo nível de investimento em educação e capital humano; desincentivo à poupança, ao investimento e ao capital físico; e baixo desenvolvimento institucional do mercado financeiro (Gylfason, 2004).

A doença holandesa é o fenômeno que valoriza a moeda nacional pela apreciação das commodities agrícolas e minerais no mercado internacional, o que inibe as exportações das demais mercadorias e os investimentos externos diretos ao mesmo tempo em que estimula a importação de produtos manufaturados. O resultado é uma especialização excessiva da economia e um aumento de sua dependência externa que podem torná-la vulnerável devido à enorme flutuação dos preços dos recursos naturais exportados in natura ou com transformações industriais de baixo valor agregado. 
Recursos naturais abundantes e instituições fracas podem trazer consequências destrutivas para a economia de um país, uma vez que dão margem a esforços para capturar privilégios de monopólio, concentrar poder político e econômico nas mãos das elites, que usam as rendas em seu favor e no suporte às políticas que defendem os seus interesses ampliando a desigualdade. Trata-se do fenômeno econômico conhecido como rent seeking que pode ser exemplificado pelo favorecimento de grandes empresas, corrupção, estabelecimentos de tarifas protecionistas. A falsa sensação de segurança que a descoberta de recursos naturais pode causar levaria os governos a perderem o foco de gerenciamento econômico adequado, deixando a desejar no fortalecimento do capital social (Gylfason, 2004) ou a um posicionamento dos empresários de maximização dos lucros individuais com sérios prejuízos para a economia como um todo (Iizuka; Katz, 2011).

Estes dois últimos pontos são também enfatizados por Buarque (2013), citando Celso Furtado e sua análise da economia venezuelana pelo abandono de sua capacidade industrial e tecnológica devido a sua riqueza natural e o Brasil por contar com recursos ainda não explorados do pré-sal para resolver o problema de nosso atraso em conhecimento e educação. Segundo o autor, estaríamos sendo vítimas da "maldição da ilusão", ao esperar renda futura para resolver um problema urgente e com necessidade de ser atacado o mais rápido possível devido ao seu longo tempo de maturação.

Em suma, essa literatura chama atenção para dois fatos: as indústrias baseadas em recursos naturais, ainda que intensivas em mão de obra altamente qualificada e também em capital de alta qualidade, como é o caso da exploração do petróleo, são incapazes por si só de gerar externalidades para a economia como um todo. Historicamente, o caso dos países que se preocupam em direcionar os efeitos em cadeia para o seu próprio país com uma política industrial e tecnológica são os casos de sucesso (Kim, 1997). Outro aspecto decorrente é que os investimentos em educação, saúde e redução da pobreza são insuficientes para estimular o acúmulo de capital humano e a acumulação tecnológica. Assim, apesar da abundância e da relevância dos recursos recebidos do petróleo, as políticas de conteúdo local e os investimentos em bens coletivos de infraestrutura são insuficientes para alterar os desafios atuais de uma economia de enclave.

Estes pontos já ficaram evidenciados a partir das dificuldades que a especialização da economia fluminense apresenta em sua taxa de crescimento do PIB, muito inferior à brasileira, ainda que o seu produto industrial tenha crescido mais rapidamente que o do Brasil. As duas seções seguintes apresentam um detalhamento desta análise.

\section{Características da exploração e produção do P\&G em Macaé: internacionalização e encadeamentos}

O processo de globalização produtiva, induzido e potencializado pelo desenvolvimento das tecnologias de informação e comunicação, leva cada vez mais a articulação entre o "local" e o "global", estimulando as relações diretas de cada região produtiva ao mercado mundial em detrimento do estabelecimento de encadeamentos no próprio país. Em especial, na indústria extrativa do $P \& G$, ainda que a localização produtiva seja mais vantajosa próxima à existência de jazidas, em geral o fornecimento de bens e serviços para a extração é bastante internacionalizado. Isto ocorre devido ao enorme conjunto de bens e serviços especializados que a atividade extrativa demanda e que devido ao elevado grau de especialização para se viabilizarem economicamente precisam exportar grande parte de sua produção.

A trajetória dos quarenta últimos anos de Macaé, município do ERJ, oferece a analise um caso bastante instrutivo de um conjunto de transformações locais induzidas por uma dinâmica ao mesmo tempo recente e importante baseada sobre uma atividade totalmente nova na região, altamente técnica e fortemente internacionalizada. O crescimento espetacular do município e de seu aparelho produtivo decorre segundo Fauré (2005a) de três séries de fenômenos que, ao se conjugarem nestes últimos anos, modificaram profundamente a identidade da cidade. O primeiro, foi a descoberta, na Bacia de Campos, nos anos 1970, de reservas de petróleo que levaram a instalação da Petrobras, principal empresa então responsável pela extração e produção de petróleo, nesta região. 
O segundo fenômeno é de certa forma responsável pela internacionalização parcial do município e está diretamente ligado às modificações realizadas ao final dos anos 1990 no regime jurídico da atividade petrolífera brasileira, inspiradas pela política de liberalização das atividades e de abertura comercial, conduzidas sob a liderança do então presidente Fernando Henrique Cardoso. A nova Lei do petróleo (Lei 9.478/1997) estabeleceu o fim do monopólio exercido após os anos 1950 pela Petrobras e abriu a prospecção e a produção petrolífera aos investimentos privados e estrangeiros. Algumas companhias petrolíferas internacionais, em associação com a Petrobras em campos nos quais ela prospectava ou que ela produzia ou em concorrência com ela em outros blocos offshore, passaram a participar da pesquisa e da produção do ouro negro.

Finalmente cabe citar o fenômeno de terceirização, resultante do novo regime de acumulação flexível, que afetou fortemente ao longo dos últimos anos a cadeia petrolífera e também teve um impacto considerável sobre as características da economia local e sobre o tecido empresarial macaense. De um lado, a Petrobras terceirizou fortemente suas atividades e, de outro, foram atraídas, para o local, empresas fornecedoras multinacionais. De fato, com a chegada destas empresas especializadas, alguma delas com atividades à escala mundial, com a instalação no local de suas prestadoras de serviços, fornecedores e subcontratadas, a paisagem macaense transformou-se sensivelmente. E mais criou uma profunda assimetria de oportunidades, gerando uma série de limites, tensões e contradições ao desenvolvimento local e que serão apontadas a seguir.

Como dito, a indústria extrativa de $\mathrm{P} \& \mathrm{G}$ fluminense desenvolve-se principalmente a partir da instalação da Petrobrás, nos anos 1970, em Macaé que deu lugar sucessivamente ao aparecimento de um aglomerado de empresas de diversos ramos de bens e serviços ligados diretamente e indiretamente às atividades extrativas de P\&G. Este aglomerado apresentou uma forte expansão e consolidação nos últimos 40 anos com a atração de novas empresas operadoras ${ }^{8}$, mas principalmente com a aceleração dos investimentos da Petrobrás. Empresa esta que é o centro deste sistema produtivo acompanhada das demais empresas operadoras. No seu entorno estão as grandes empresas offshore em sua maioria multinacionais, voltadas para a prestação de serviços altamente especializados, empresas nacionais e multinacionais de engenharia ${ }^{9}$, denominadas epcistas ${ }^{10}$, e as pequenas e médias empresas (PMEs), majoritariamente nacionais e que atuam basicamente como subcontratadas.

Segundo Silva e Britto (2009) este aglomerado apresenta características de um modelo centro-radial, proposto por Ann Markusen. Segundo os autores, a literatura demonstra que neste tipo de arranjo é comum se observar uma enorme assimetria entre as empresas operadoras e as empresas radiais. Fauré (2005b) denomina-o de um quase-cluster porque as ligações bilaterais estabelecidas entre a Petrobras e as demais operadoras e o conjunto das empresas fornecedoras e subcontratadas instaladas em Macaé, não denotam uma verdadeira divisão vertical e localizada do trabalho no setor. Ainda segundo o autor há ausência de cooperações horizontais como, por exemplo, serviços e infraestruturas compartilhados entre elas. Torna-se evidente, a partir de ambas as tipificações propostas sobre o aglomerado, que se trata menos de um distrito industrial com efeitos virtuosos de aglomeração e mais de uma concentração espacial de fornecedores capazes de reduzirem os custos de transação da Petrobrás e demais empresas operadoras.

Seguindo a caracterização de Silva e Britto (2009), entre as empresas radiais encontramse as empresas contratadas, em geral dotadas de menor poder financeiro e tecnológico e as subcontratadas, em sua maioria, pequenas e médias empresas (PMEs), em maior número no aglomerado e também responsáveis por grande parcela dos empregos. Esta desigualdade leva a processos de concentração industrial que afetam particularmente as empresas menos competitivas da cadeia e as que geram mais empregos locais que são as pmes, restringindo a estruturação de uma rede com maior capilaridade e reforçando a assimetria da estrutura industrial do aglomerado. A desigualdade de competição entre as empresas fornecedoras locais e internacionais, por sua vez, se torna maior devido a confiança que precisa se estabelecer entre as várias empresas do aglomerado, conforme descrito a seguir.

8 Shell, Total Fina Elf, Exxom Mobil, Pan Canadian, Chevron, Texaco, Agip, dentre outras.

9 Halliburton, Schulumberger, Transocean, Wheaterfod e Pride são exemplos.

10 Este é o acrônimo utilizado para denominar as empresas fornecedoras de serviços de engenharia (E), suprimentos (P de procurement em inglês) e construção (C) integrados para as operadoras. 
O segmento de produção offshore de $\mathrm{P} \& \mathrm{G}$ é um sistema técnico-produtivo que possui uma operação complexa, ou seja, envolve um número enorme de componentes sob medida, uma enorme amplitude de conhecimentos e habilidades antigos e novos para a exploração e produção do petróleo, requerendo a integração de diferentes sistemas de componentes. Os bens e serviços gerados são sofisticados, intensivos em engenharia e tecnologia e têm um valor agregado alto. Desta forma os fornecedores da Petrobrás e das demais operadoras, denominados o segmento primário ou núcleo da rede, desenham e configuram seus produtos ou serviços de acordo com os requerimentos destas contratantes que envolvem estudos detalhados de engenharia e simulações complexas da operação dos sistemas envolvidos. As empresas operadoras são centrais, pois a elas cabe o direcionamento e o planejamento das atividades de inovação e de difusão tecnológica, necessários à exploração e produção do petróleo. Devido à maturidade do setor algumas vezes empresas de engenharia a serviço das operadoras se responsabiliza pelo desenvolvimento de projetos, assumindo o papel de contratante principal, através da subcontratação de outras empresas fornecedoras de equipamentos e serviços ${ }^{11}$. Percebe-se, portanto, que a relação entre os fornecedores e as contratantes ou as contratantes principais são muito estreitas para que este sistema técnico -produtivo possa funcionar com eficiência e eficácia, fazendo com que muitas vezes os fornecedores nacionais sejam preteridos pelas empresas estrangeiras que preferem continuar se relacionando com os seus fornecedores internacionais. Este problema tende a se agravar à medida que novos grupos estrangeiros passem a figurar entre as contratantes principais, prestando serviços à Petrobras.

A tendência que se tem observado deste fenômeno de crescente terceirização das operadoras é que uma parte significativa das PMEs, as de menor nível de capacitação tecnológica tenderão a desaparecer por não atender os requisitos mínimos de qualidade, produção, capital, qualificação da mão de obra, exigidos e por terem perdido as oportunidades de capacitação que a Petrobrás, quando as contratava diretamente, lhes oferecia. Ilustrativo deste movimento foi a criação em Macaé do Grupo de Empresas Prestadoras de Serviços na Indústria de $P \& G$ para se protegerem dos efeitos negativos da reorientação da política de contratação da Petrobrás.

Observa-se, desta forma, que as características do aglomerado de empresas responsáveis pela exploração e produção do $P \& G$, localizadas em Macaé, foram construídas a partir da descoberta do petróleo na bacia de Campos e o aglomerado já nasceu fortemente internacionalizado devido às características técnico-produtivas da atividade petrolífera, regime de concessão de exploração do recurso natural que estimulou a vinda de novas operadoras a partir de 1997 e adoção de um regime de produção mais flexível que levou a Petrobras terceirizar suas atividades de engenharia para empresas denominadas de contratantes principais. Todo este processo impediu que as vantagens das externalidades positivas geradas por aglomerados de empresas pudessem transformar este aglomerado em um polo de desenvolvimento local dinâmico e capaz de ampliar o bem estar das populações locais.

Na próxima seção, se verá em que medida o poder público em sua escala nacional tem atuado frente a estas mudanças tão drásticas de articulação entre o local e o global e avaliar preliminarmente os seus resultados sobre o desenvolvimento através de indicadores sociais.

\section{Avaliação das políticas e dos indicadores de desenvolvimento}

Nesta seção - composta de duas subseções - apresentam-se, inicialmente, uma avaliação das políticas voltadas para o aumento do conteúdo local e, a seguir, os indicadores de renda e emprego, saúde e educação e as dificuldades desta economia em alcançar um desenvolvimento virtuoso e transformador das condições socioeconômicas de sua indústria e população.

11 Entre as contratantes principais atuando no Brasil encontram-se as seguintes empresas: Technint, Ultratec, Montreal, Camargo Correa, Odebrecht, Setal, Promon, Marítima. Observa-se também crescente participação de grupos estrangeiros tais como ABB-Lumus Global, Bechtel, Foster Wheeler, Kellogg Brown \& Root. 


\section{Resultados das políticas de estímulo industrial e tecnológico}

É possível identificar na política industrial brasileira direcionamentos que tentam, ainda que se possa questionar seu sucesso, aproveitar o bom momento do mercado internacional de commodities para gerar efeitos de capacitação dos produtores nacionais fornecedores da indústria petrolífera e evitar a sua extrema dependência de importação de bens e serviços. A política de conteúdo local da Agência Nacional do Petróleo, Gás Natural e Biocombustíveis (ANP) obriga não somente a Petrobras, mas também as demais empresas produtoras de petróleo a priorizar as empresas nacionais em suas compras de bens intermediários e de capital.

Entretanto, parece que esta política tem sido questionada devido à baixa capacidade de resposta da indústria local em atender a demanda acelerada dos investimentos para exploração do pré-sal. De fato, em notícia publicada no jornal $O$ Globo de 01/03/2013 a Petrobras solicitava a redução da exigência de conteúdo nacional em 43 itens.

Talvez essa notícia esteja apenas preparando terreno para que a Petrobrás se beneficie do Regime Aduaneiro Especial de Exportação e Importação de Bens Destinados à Exploração e à Produção de Petróleo e Gás Natural (Repetro). Trata-se de outra política industrial que concede temporariamente a suspensão de tributos à importação de alguns insumos para a produção de petróleo, com o objetivo de garantir a operacionalidade da indústria, servindo como uma salvaguarda da política de conteúdo local no caso de não haver empresas nacionais capacitadas para atender às demandas do setor. Para se beneficiar do regime, a empresa produtora fica comprometida a depositar em garantia o valor do tributo suspenso e reexportar o equipamento importado ao final do uso. Assim, o Repetro abre margem de contorno para as empresas concessionárias a importarem máquinas e equipamentos ao invés de comprá-los localmente.

O relato dos dois parágrafos acima reforça a importância da ação coordenada de diferentes políticas e representa o grande desafio para o aproveitamento dos recursos naturais para promover a transição econômica desejada. Isto porque a política de conteúdo local está sob a responsabilidade do Ministério das Minas e Energia e a política industrial está sob a responsabilidade do Ministério de Desenvolvimento, da Indústria e do Comércio, dificultando a coordenação.

Outro aspecto a considerar sobre a política é que se, por um lado, fornece a oportunidade de a empresa local desenvolver-se a partir do fornecimento de insumos e equipamentos para a indústria extrativa, por outro, também fornece um mercado protegido a ela, que pode induzir a comportamentos rentistas e gerar ineficiência na cadeia de valor. Além disso, essa estratégia só é viável se houver empresas nacionais capacitadas a fornecer os insumos para a indústria extrativa principal (Xavier Jr, 2012) o que, como mostrado por Oliveira e Rocha (2008), parece não ser o caso apesar do Programa de Mobilização da Indústria Nacional de Petróleo e Gás Natural (Prominp).

De fato, o Prominp foi lançado, em 2003, pelo governo federal com o objetivo de aumentar a participação das empresas brasileiras nessa indústria, mediante investimento e suporte ao empresariado, representando um sustentáculo da política de conteúdo local. Entretanto, Oliveira e Rocha (2008) apontaram a existência de lacunas produtivas, identificando falta de competitividade do setor industrial nacional originária de limitada capacitação inovativa das empresas e da fragilidade da engenharia nacional. Outro aspecto relatado por esses pesquisadores refere-se às dificuldades de coordenação da cadeia produtiva, em especial quanto ao papel das firmas de engenharia, construção e montagem (EPCistas), tendo em vista que o Brasil não conta, como no caso da Noruega, de uma rede cooperativa de inovação, que favorece o fluxo de conhecimento e a produção pelo envolvimento da operadora, dos EPCistas, das firmas industriais e empresas de serviços, bem como com a participação das universidades e centros de pesquisa, concorrendo para o desenvolvimento da capacitação tecnológica da indústria de petróleo e gás (Gylfason, 2004).

Quanto às lacunas apontadas, as principais estão na indústria de transformação: siderurgia (segmentação) ${ }^{12}$; Calderaria (tecnologia); navipeças - válvulas (tecnologia), bombas e subestação-transformadores (metrologia), compressores, motores diesel e a gás, turbinas, guindastes e guinchos, sistemas subsea, instrumentação (escalas de produção). O que re-

12 Entre parêntesis são indicadas as razões principais da lacuna. 
força a necessidade de políticas coordenadas, combinando políticas de conteúdo local com as políticas industrial e tecnológica. Outra lacuna está na capacitação tecnológica dos epcistas. Apesar de Oliveira e Rocha (2008) terem identificado que os fornecedores da indústria petrolífera desenvolvem atividades inovadoras em ritmo superior à média das firmas brasileiras ${ }^{13}$, advém em geral da cooperação entre firmas da cadeia produtiva. Porém, os gastos nas atividades de inovação das empresas locais são reduzidos, com uma razão entre gastos em P\&D e o faturamento dos fornecedores da indústria de petróleo e gás em torno de $0,65 \%$. Essa razão é muito inferior ao que é praticado em semelhantes firmas no mundo, representando um risco de perda de competitividade crescente da indústria do petróleo e gás, caso esses investimentos em P\&D não sejam ampliados adequadamente, dando vantagens competitivas aos fornecedores da cadeia global.

Além da política de conteúdo local, a ANP possui o Programa de Recursos Humanos (PRH-ANP), financiado pelo Fundo Setorial do Petróleo e Gás Natural (CT-PETRO), que tem por objetivo formar pessoal especializado de nível superior para trabalhar na indústria petrolífera. No diagnóstico realizado por Oliveira e Rocha (2008), é importante mencionar que o elemento determinante para a fragilidade das empresas de engenharia é uma limitada oferta de mão de obra qualificada, apesar do PRH-ANP.

Em relação ao estímulo à inovação, observa-se que o CT-Petro não foi capaz de articular a contento as empresas locais com o sistema científico e tecnológico nacional. Esta percepção é derivada da constatação de que o potencial disponível em universidades e centros de $\mathrm{P} \& \mathrm{D}$, bem como o sistema de infraestrutura científica e tecnológica (sistema de normatização e metrologia) não tem sido utilizado pelo sistema produtivo de petróleo e gás (Oliveira e Rocha, 2008). Uma razão pode ser o contingenciamento de recursos desse fundo, outra razão pode ser a insuficiência de realização de atividades de P\&D das empresas, por falta de recursos financeiros ou por ausência de posicionamento estratégico, com baixos gastos em P\&D das empresas de petróleo e gás, conforme informado acima.

Diante desse contexto, foi lançado em 2012 o Programa Inova Petro, resultado de uma parceria entre a Financiadora de Estudos e Projetos (FINEP) e o Banco Nacional de Desenvolvimento Econômico e Social (BNDES), além de contar com o apoio técnico da Petrobras. Tal programa tem duração prevista até 2017 e dispõe, inicialmente, de R\$ 3 bilhões. O objetivo principal do Inova Petro é desenvolver o parque nacional de fornecedores da indústria de petróleo e gás a partir do fomento de projetos envolvendo $\mathrm{P} \& \mathrm{D}$, engenharia, absorção tecnológica e processos e serviços inovadores, buscando-se tanto o aumento do conteúdo local como o desenvolvimento da competitividade dos fornecedores nacionais.

Outras ações governamentais e não governamentais de apoio à indústria petrolífera também desempenham um papel importante no país: o Instituto Brasileiro de Petróleo, Gás e Biocombustíveis, entidade privada sem fins lucrativos que é responsável por promover a difusão de informação e discussão de temas relevantes no setor; a Organização Nacional da Indústria do Petróleo é uma entidade privada sem fins lucrativos que busca promover a cooperação entre as companhias evolvidas na extração, produção, refino, processamento, transporte e distribuição de petróleo e seus derivados, sendo responsável pela certificação de qualidade das empresas candidatas a fornecedoras da indústria e funciona como fórum de discussão e de proposição de melhorias da política industrial do setor.

\section{Indicadores de renda e emprego, saúde e educação}

Por meio do Índice FIRJAN de Desenvolvimento Municipal (IFDM) ${ }^{14}$, será apresentada a situação dos municípios do ERJ e a sua posição relativa frente aos principais estados do país no que diz respeito ao seu potencial de desenvolvimento regional, bem como, por meio de estudos recentes, será enfocado o desenvolvimento das ações do ERJ nas áreas de emprego e renda, saúde e educação (FIRJAN, 2012). Esta é uma forma de avaliar se os recursos arrecadados com o petróleo estão sendo empregados de forma a ampliar as capacidades das populações locais e facilitar o crescimento da renda e do emprego.

13 Um terço das inovações de produto e pouco menos de 15\% em processo.

14 Para um detalhamento da metodologia do IFDM consultar FIRJAN (2012). 
A Tabela 4 apresenta o resultado geral do IFDM para os estados brasileiros. São apresentados os resultados de 2000 e comparados com os de 2010 apenas para as seis unidades da federação mais bem classificadas.

Tabela 4: IFDM Global e seus componentes (Emprego e Renda, Educação e Saúde) para os estados brasileiros, 2000 e 2010

\begin{tabular}{|c|c|c|c|c|c|c|c|c|c|c|c|c|}
\hline \multirow{2}{*}{ UF } & \multicolumn{3}{|l|}{ IFDM } & \multicolumn{3}{|c|}{ Emprego e Renda } & \multicolumn{2}{|c|}{ Educação } & \multicolumn{3}{|c|}{ Saúde } & \multirow[b]{2}{*}{ Var. $\%$} \\
\hline & 2000 & 2010 & Var. $\%$ & 2000 & 2010 & Var. $\%$ & 2000 & 2010 & Var. \% & 2000 & 2010 & \\
\hline SP & 0,73 & 0,89 & 23 & 0,59 & 0,88 & 49 & 0,8 & 0,91 & 15 & 0,78 & 0,88 & 13 \\
\hline PRO, & 0,65 & 0,84 & 29 & 0,48 & 0,84 & 76 & 0,69 & 0,8 & 16 & 0,8 & 0,89 & 12 \\
\hline SC & 0,64 & 0,83 & 29 & 0,49 & 0,78 & 60 & 0,69 & 0,84 & 20 & 0,73 & 0,86 & 17 \\
\hline RJ & 0,66 & 0,82 & 24 & 0,56 & 0,87 & 56 & 0,66 & 0,77 & 16 & 0,77 & 0,83 & 7 \\
\hline MG & 0,63 & 0,82 & 30 & 0,52 & 0,83 & 58 & 0,66 & 0,81 & 22 & 0,71 & 0,83 & 16 \\
\hline RS & 0,65 & 0,82 & 26 & 0,53 & 0,83 & 58 & 0,64 & 0,75 & 18 & 0,78 & 0,87 & 11 \\
\hline Média Br. & 0,60 & 0,79 & 33 & 0,49 & 0,79 & 62 & 0,59 & 0,77 & 31 & 0,71 & 0,81 & 14 \\
\hline Mediana Br. & 0,55 & 0,72 & 30 & 0,48 & 0,61 & 27 & 0,5 & 0,73 & 44 & 0,64 & 0,78 & 21 \\
\hline
\end{tabular}

Fonte: Elaboração própria com base no IFDM/FIRJAN (2008-2012)

O ERJ tem um aumento de $24 \%$ de seu IFDM entre 2000 e 2010 , mas o seu crescimento relativo foi inferior ao de outros estados brasileiros fazendo com que ele se deslocasse da terceira posição no ranking brasileiro para a quarta posição, ainda que o seu desempenho em 2010 seja superior à média e à mediana do Brasil. Liderando o ranking se encontram São Paulo, Paraná e Santa Catarina, nesta ordem, sendo os dois últimos estados não produtores de petróleo. Destaque deve ser dado ao desempenho de Santa Catarina na evolução dos indicadores de educação e saúde e ao do Paraná no de emprego e renda que são superiores ao do ERJ no período.

No caso do ERJ, o pior resultado dos componentes do IFDM está na área de educação, ligeiramente acima da mediana e da média nacionais, sendo considerado um desenvolvimento moderado. ${ }^{15}$ Este resultado é muito abaixo do terceiro estado colocado (SC) e ainda inferior ao do quinto colocado, Minas Gerais, em 2010. Emprego e renda puxam o índice global para cima, refletindo o bom desempenho econômico do Estado, mas que também não é acompanhado pelo indicador de saúde. Desta forma, pode-se supor ou que os ganhos gerados com a economia do petróleo ainda estão sendo reinvestidos na economia fluminense em uma proporção inadequada para mudar as capacidades da população (educação e saúde) ou que estes investimentos estão sendo adiados, conforme constatado na seção anterior.

A área de saúde no ERJ, segundo Munoz (2011), apresenta a seguinte caracterização. Apesar de possuir a maior quantidade de médicos e leitos por habitante do país e um dos maiores gastos públicos, uma análise comparada mostra que a população do ERJ é a que menos utiliza o SUS na região sudeste, com 2,3 consultas/ano, ante uma média de 3,2 vezes para São Paulo e 2,6 vezes para Minas Gerais. O mesmo se dando com internações, com a média de 3,2 internações por 100 habitantes para uma média da região sudeste de 5,2.

Comparando-se os índices de mortalidade do ERJ com os demais estados do sudeste, os resultados para câncer de mamas e de colo de útero são piores para o ERJ em $100 \%$ em relação a Minas Gerais e em 60\% em relação a São Paulo, para o ano de 2008 (Munoz, 2011). Outros pesquisadores ${ }^{16}$ apontam índices de mortes evitáveis devido a falhas de qualidade da assistência à saúde no ERJ (mortalidade neonatal; qualidade de assistência ao parto).

De forma comparada, a partir da Tabela 4 percebe-se que, sem dúvida, houve uma melhora da situação de saúde no ERJ, entre 2000 e 2010, mas seu desempenho melhorou apenas em $7 \%$ muito inferior ao da média brasileira (14\%) e ainda mais à mediana (21\%). Isto pode estar indicando que questões de governança no sistema ainda carecem de solução. Segundo Munoz (2011), um estudo de 2007 do Banco Mundial identificou a pouca possibi-

15 Classificação por IFDM: entre 0 e 0,4 baixo estágio de desenvolvimento; entre 0,4 e 0,6 desenvolvimento regular; entre 0,6 e 0,8 desenvolvimento moderado; e entre 0,8 e 1 alto estágio de desenvolvimento.

16 Leal e Szwarcwald (1996) e Oliveira et al. (2008) apud Munoz (2011). 
lidade de ação gerencial e o pouco controle orçamentário por parte dos gestores. Para o autor, no caso do ERJ, a falta de articulação entre as três esferas de poder, dado também que o erj reagiu tardiamente à mudança de modelo, comprometeu os resultados de saúde da população. Também não há previsão de instância político-institucional com poder deliberativo para fazer planejamento regional e para a coordenação intermunicipal no estado.

Em relação à educação, na Tabela 4, constata-se que o ERJ se manteve com a classificação de desenvolvimento moderado, ocupando a quinta posição entre os seis melhores estados da federação. A evolução do seu desempenho, entre 2000 e 2010, entretanto, foi muito inferior ao brasileiro ( $16 \%$ contra a evolução da média de $31 \%$ e a evolução da mediana de $44 \%$ para o Brasil).

$\mathrm{Na}$ análise por faixas etárias, $40 \%$ dos jovens de 15 a 17 anos ainda estão no ensino fundamental e na faixa de 18 a 24 anos, apenas $34,5 \%$ prosseguem estudando. Desses, somente $18 \%$ chegam ao ensino superior. Subindo a faixa, para os maiores de 24 anos, 95,5\% dos indivíduos não estudam (Schwartzman, 2011).

Os resultados apresentados por Schwartzman (2011) são congruentes, para o caso do ERJ, com o Índice de Desenvolvimento da Educação Básica para o ano de 2009. Nesse ano, para o $5^{\circ}$ ano, os melhores desempenhos foram do Paraná $(4,2)$, Santa Catarina $(4,1)$ Minas Gerais e Rio Grande do Sul $(3,8)$. Com o índice de 3,3, o ERJ situou-se no nível médio do Nordeste.

Nessa área há muitos desafios a vencer para o erj e seus municípios. O governo estadual ainda divide com as prefeituras o segmento superior de educação fundamental $5^{\circ}$ ao $9^{\circ}$ ano e participa parcialmente do primeiro segmento. No município do Rio de Janeiro, seguindo a tendência nacional, a quase totalidade do ensino fundamental é de sua responsabilidade, ficando o segmento do ensino médio com o governo estadual (Schwartzman, 2011).

No estado do Rio de Janeiro, a Lei Estadual $n^{\circ}$ 5.597/2009 instituiu o Plano Estadual de Educação formulado pela Secretaria de Estado de Educação, a Assembléia Legislativa do estado do Rio de Janeiro e entidades civis, com propostas concretas para melhorar a educação. O plano, todavia, parece ter perdido impulso já em 2010, em virtude de mudanças no comando da pasta e subsequente estabelecimento do novo Programa de Educação do Estado.

\section{Conclusão}

A fotografia realizada sobre a especialização do ERJ e os seus desafios permite afirmar que, utilizando os termos da CEPAL (2012), parece estar em curso no ERJ um padrão de desenvolvimento caracterizado por mudança estrutural limitada a enclaves, com baixo crescimento da demanda agregada e forte aumento da produtividade em poucos setores (principalmente indústrias de bens intermediários). Em outras palavras, o direcionamento da mudança estrutural observada ainda se encontra longe do desejável, qual seja o de um padrão de desenvolvimento virtuoso, que favoreça os setores dinâmicos com alto conteúdo tecnológico e fortaleça os encadeamentos produtivos internos, com ganhos de produtividade significativos, aumentos salariais e melhorias sociais.

Ainda que seja possível identificar na política industrial brasileira direcionamentos que tentam aproveitar o bom momento do mercado internacional de commodities para gerar efeitos de capacitação dos produtores nacionais, parece que estas políticas não estão surtindo o efeito desejado, seja porque a resposta a elas ainda é pequena seja porque a coordenação entre as várias políticas ainda deixe a desejar. A interrupção do momento positivo do ambiente internacional, observado entre 2004 e 2007, tornou menos favorável à exploração de recursos naturais a partir de 2008, mas os problemas com as políticas de conteúdo local são recorrentes durante todo o perídio analisado.

Conclui-se que, ainda que se tenha identificado ações positivas para afastar a doença holandesa, os recursos gerados pela exploração da atividade petrolífera estão sendo desviados para finalidades outras que não a promoção do desenvolvimento sustentável. Parte destes recursos acaba sendo canalizada para a importação de insumos que a indústria local não tem condições de ofertar no tempo desejado, impedindo o fortalecimento da indústria local e a sua diversificação. Outra parte para importar mão de obra qualificada que a indústria não encontra no Brasil, impedindo o engajamento da população local nas atividades produtivas petrolíferas e o crescimento da demanda agregada. Além disso, os recursos 
obtidos com as rendas do petróleo não têm sido aplicados em bens públicos capazes de garantir a sustentabilidade do desenvolvimento no longo prazo.

Finalmente, é importante registrar que a discussão, ainda em curso, sobre a mudança na regra de distribuição dos recursos, trazida pela Lei 12.351/2010, nada mudará no sentido do reconhecimento da importância do investimento na diversificação das atividades petrolíferas, ampliação do uso de insumos de conteúdo local e ampliação de suas capacidades na oferta de bens coletivos e infraestrutura. Isso porque as elites locais serão apenas trocadas pelas elites nacionais e, como visto, nem uma nem outra tem demonstrado compromisso com investimentos no país e no bem estar das populações e apenas visam manutenção do status quo.

\section{Referências bibliográficas}

ANP. Agência Nacional do Petróleo, Gás Natural e Biocombustiveis. (2012). Anuário estatístico brasileiro do petróleo e do gás natural 2012. Rio de janeiro: ANP. Disponivel em http://www.anp.gov.br. Acesso em 12 abr 2013.

BARBOSA, D.H. (Coord.). (2001). Guia dos royalties do petróleo e do gás natural / Agência Nacional do Petróleo. Rio de Janeiro: ANP, 2001.

BUARQUE, C. (2013). Maldição da ilusão. Jornal 0 Globo, 20 de abril.

CEPAL (2012). Cambio estructural para la igualdad: Una visión integrada Del desarrollo. Trigésimo cuarto período de sesiones de la CEPAL, San Salvador, ago.

EVANS, Peter B. (2010) Construction the 21st century Developmental State: Potentials and pitfalls.

In: Edigheji, Omano (ed.) Constructing a democratic developmental State in South África potentials and challenges, HSRC Press, Capetown, South África, p.37-58.

FAURÉ, Yves-Andre. Macaé: Internalizar as oportunidades do petróleo e diversificar a economia municipal. In: Fauré, Y-A; Hasenclever, L. 0 desenvolvimento local no estado do Rio de Janeiro: estudos avancados nas realidades municipais. Rio de Janeiro:

Editora E-papers, 2005a, p.215-322.

Le monde est arrivé à Macaé (Brésil). Avancées et limits d'une configuration productive local globalisé. In: Fauré, Y-A.; Kennedy, L.; Labazée, P. Productions Locales et Marché Mondial dans les Pays Émergents. Paris: Karthala Editions/ird, cp. 3, p.89-128, $2005 b$

FIRJAN. Federação das Indústrias do estado do Rio de Janeiro. (2012). Índice firjan de desenvolvimento municipal: ano base 2010 .

GYLFASON, T. (2004). Natural resources and economic growth: from dependence to diversification. In: Sustainable Economic Liberalization and Integration Policy:
Options for Eastern Europe and Russia, University of Wuppertal, Germany.

IIZUKA, M; Katz, J. (2011). Natural resource industries, 52 tragedy of the commons and the case of Chilean salmon farming. International Journal of Institutions and Economies, Vol. 3, No. 2, jul., p.259-286.

KIM, L. (1997). Da imitação à inovação: a dinâmica do aprendizado tecnológíco da Coreia. Tradução de Maria Paula G.D. Rocha. Clássicos da Inovação. Campinas, SP. Editora da Unicamp, 2005.

MUNOZ, F.P. A saúde no Rio de Janeiro: o velho compromisso pendente. In Urani, A.; Giambiagi, F. (orgs.). Rio: a hora da virada. Rio de Janeiro: Elsevier, 2011.

OLIVEIRA, A.; Rocha, C.F.L. (2008). Estudo da competitividade brasileira de bens e serviços do setor de petróleo e gás: conclusões e recomendações de política. Mimeo: Prominp/IE-UFRJ.

ORDONEZ, R.; Rosa, B. Petrobras quer rever conteúdo local na $11^{\mathrm{a}}$ rodada. 0 Globo, Caderno Economia, p.33, $1^{\circ}$ de marco de 2013

SCHWARTZMAN, Simon. Melhorar a educação no Rio de Janeiro: um longo caminho. In Urani, A.; Giambiagi, F. (orgs.). Rio: a hora da virada. Rio de Janeiro: Elsevier, 2011.

SILVA, R.C.R.; Britto, J. 0 aglomerado de empresas atuantes no segmento offshore de Macaé: impactos da política de subcontratacão da Petrobrás na Bacia de Campos. Revista Brasileira de Inovação, v. 8, n.1, p.121-166, já.jun. 2009.

TCE-RJ. Tribunal de Contas do Estado do Rio de Janeiro. (2011). Estudos socioeconômicos dos municípios do estado do Rio de Janeiro: comparativo dos municípios fluminenses.

XAVIER JR, C.E.R. (2012). Políticas de conteúdo local no setor petrolifero: 0 caso brasileiro e a experiência internacional. Texto para discussão. Rio de Janeiro: Ipea, n. 1775 , out. 